\title{
Sulfated vizantin causes detachment of biofilms composed mainly of the genus Streptococcus without affecting bacterial growth and viability
}

Taisuke Hasegawa $^{1 \dagger}$, Shoji Takenaka ${ }^{1 * \dagger}$, Masataka Oda ${ }^{2}$, Hisanori Domon ${ }^{3}$, Takumi Hiyoshi, ${ }^{3,4}$, Karin Sasagawa ${ }^{3,4}$, Tatsuya Ohsumi ${ }^{1}$, Naoki Hayashi ${ }^{2}$, Yasuko Okamoto ${ }^{5}$, Hirofumi Yamamoto ${ }^{6}$, Hayato Ohshima ${ }^{7}$, Yutaka Terao ${ }^{3}$ and Yuichiro Noiri ${ }^{1}$

\begin{abstract}
Background: Sulfated vizantin, a recently developed immunostimulant, has also been found to exert antibiofilm properties. It acts not as a bactericide, but as a detachment-promoting agent by reducing the biofilm structural stability. This study aimed to investigate the mechanism underlying this activity and its species specificity using two distinct ex vivo oral biofilm models derived from human saliva.

Results: The biofilm, composed mainly of the genus Streptococcus and containing $50 \mu \mathrm{M}$ of sulfated vizantin, detached significantly from its basal surface with rotation at $500 \mathrm{rpm}$ for only $15 \mathrm{~s}$, even when $0.2 \%$ sucrose was supplied. Expression analyses for genes associated with biofilm formation and bacterial adhesion following identification of the Streptococcus species, revealed that a variety of Streptococcus species in a cariogenic biofilm showed downregulation of genes encoding glucosyltransferases involved in the biosynthesis of water-soluble glucan. The expression of some genes encoding surface proteins was also downregulated. Of the two quorum sensing systems involved in the genus Streptococcus, the expression of luxS in three species, Streptococcus oralis, Streptococcus gordonii, and Streptococcus mutans, was significantly downregulated in the presence of $50 \mu \mathrm{M}$ sulfated vizantin. Biofilm detachment may be facilitated by the reduced structural stability due to these modulations. As a non-specific reaction, $50 \mu \mathrm{M}$ sulfated vizantin decreased cell surface hydrophobicity by binding to the cell surface, resulting in reduced bacterial adherence.
\end{abstract}

Conclusion: Sulfated vizantin may be a candidate for a new antibiofilm strategy targeting the biofilm matrix while preserving the resident microflora.

Keywords: Biofilm, Detachment, Streptococcus, Functional molecule, Glucosyltransferase, Gene expression

\footnotetext{
* Correspondence: stakenaka@dent.niigata-u.ac.jp

†Taisuke Hasegawa and Shoji Takenaka contributed equally to this work.

'Division of Cariology, Operative Dentistry and Endodontics, Faculty of

Dentistry \& Graduate School of Medical and Dental Sciences, Niigata

University, 2-5274, Gakkocho-dori, Chuo-ku, Niigata 951-8514, Japan

Full list of author information is available at the end of the article
}

(c) The Author(s). 2020 Open Access This article is licensed under a Creative Commons Attribution 4.0 International License, which permits use, sharing, adaptation, distribution and reproduction in any medium or format, as long as you give appropriate credit to the original author(s) and the source, provide a link to the Creative Commons licence, and indicate if changes were made. The images or other third party material in this article are included in the article's Creative Commons licence, unless indicated otherwise in a credit line to the material. If material is not included in the article's Creative Commons licence and your intended use is not permitted by statutory regulation or exceeds the permitted use, you will need to obtain permission directly from the copyright holder. To view a copy of this licence, visit http://creativecommons.org/licenses/by/4.0/. The Creative Commons Public Domain Dedication waiver (http://creativecommons.org/publicdomain/zero/1.0/) applies to the data made available in this article, unless otherwise stated in a credit line to the data. 


\section{Background}

Numerous and diverse microorganisms reside in the intraoral environment, creating multispecies microbial communities that form an oral biofilm [1]. Within such a biofilm population, cells demonstrate genetic and physiological heterogeneity as they adapt to the local environmental conditions [2]. Unless these biofilms are appropriately controlled, they accumulate and contribute to tooth decalcification and periodontal inflammation [3-5].

In contrast, the natural oral microbiota has a symbiotic or mutualistic relationship with the host, and delivers important benefits. The commensal bacteria act as developers of proper tissue structure and function as well as host protection simply by niche occupation [6]. Thus, the ideal antibiofilm strategy is to control oral biofilms to levels compatible with oral health while preserving the natural and beneficial properties of the resident oral microflora [7].

Antimicrobial agents have been formulated into many oral care products to augment mechanical elimination $[8,9]$. The mechanisms of most of these agents are based on a bactericidal effect by retaining them in the mouth for relatively long periods at sublethal levels. However, increasing evidence indicates some adverse influences of an antibiofilm strategy relying on bactericidal activity. It has been reported that no or little biofilm structure is removed when oral biofilms are treated with chemical compounds such as mouthwashes [10-12]. The residual structure thus serves as a scaffold for biofilm redevelopment [13]. More recent investigations raised an alarm on the long-term use of antimicrobials due to the risk of the emergence of antimicrobial resistant bacteria $[14,15]$. Disruption of this community may create dysbiosis, contributing to dental caries, periodontal disease, and an associated increased risk of various diseases such as diabetes, atherosclerotic vascular diseases, and rheumatoid arthritis [6]. Therefore, an ideal antibiofilm strategy would be to reduce the amount of biofilm quantitatively while maintaining the proportion of each resident bacterial species qualitatively, using a method other than eradication.

Vizantin, which is a derivative of trehalose-6,6-dimycolate, is extracted from Mycobacterium tuberculosis and activates the innate immune response through specific binding to the toll-like receptor 4 /myeloid differentiation factor 2 protein complex without inducing tumor necrosis factor- $\alpha$ production [16]. Recently, we found that sulfated vizantin (Viz-S), which is a solubilized vizantin, also disrupts biofilms formed by Streptococcus mutans [17]. Viz-S inhibits bacterial adhesion without affecting bacterial growth and alters its internal architecture. Although Viz-S does not inhibit biofilm maturation of $S$. mutans, it reduces its structural stability, resulting in biofilm detachment. However, the mechanism associated with this activity and its species specificity remains unclear. This study aimed to answer these questions by utilizing two distinct ex vivo oral biofilm models derived from human saliva.

\section{Results}

Influence of Viz-S on cytotoxicity and bacterial growth

The cytotoxicity assays showed that Viz-S at concentrations less than $50 \mu \mathrm{M}$ did not affect the human gingival epithelial cells (HGECs) and human gingival fibroblasts (HGFs) (Fig. 1a and b). When estimating the influence of Viz-S against bacterial growth based on their values of optical density of the culture at $600 \mathrm{~nm}\left(\mathrm{OD}_{600}\right)$, no discernible effect was observed. Even at the maximum concentration of $100 \mu \mathrm{M}, \mathrm{Viz}-\mathrm{S}$ did not show an antimicrobial effect against bacteria derived from human saliva (Fig. 1c). Considering biological safety as well as protection of resident microflora, Viz-S at a maximum concentration of $50 \mu \mathrm{M}$ was selected for further analyses.

\section{Influence of Viz-S on biofilm formation and structural stability}

The presence of Viz-S in samples with up to $50 \mu \mathrm{M}$ of Viz-S did not inhibit maturation in both cariogenic biofilm (CB) and gingivitis biofilm (GB) after 24 h (Table 1). Although the amounts of protein and carbohydrate constituents showed a tendency to increase in a concentrationdependent, there were no significant differences in protein and carbohydrate volumes $(p>0.05)$. CB was relatively richer in the amounts of protein and carbohydrate than $G B$ irrespective of Viz-S.

The adherence of CB containing $50 \mu \mathrm{M}$ Viz-S was not strong and the biofilm was easily peeled off by slight movement (See the supplemental movie file). Viz-S at a concentration of $100 \mu \mathrm{M}$ prevented the bacteria from bacterial adhesion (See the supplemental movie file). When a shaking motion was applied to CB for only $15 \mathrm{~s}$, the biofilm developed in the presence of $50 \mu \mathrm{M}$ Viz-S lost its shape, and was almost completely detached from the lower surface (Fig. 1d, e, $p<0.05$ ). The GB had a reduced volume after 15-s rotation even in the absence of Viz-S (Fig. 1d, e). CB was structurally more stable than GB if Viz-S was not included. Prolonged agitation did not contribute to the structural degradation of $\mathrm{CB}$ in the control (without Viz-S) and in the $10 \mu \mathrm{M}$ Viz-S group. Three-dimensional reconstruction images also showed that the residual structure of $\mathrm{CB}$ containing $50 \mu \mathrm{M}$ of Viz-S was scarcely detected; however, the remaining bacteria were still alive, showing that all cells were stained with green fluorescence (Fig. 1f). Based on these findings, further analyses were focused on the constituent bacteria in the $\mathrm{CB}$ for elucidating the mechanisms associated with this activity. 

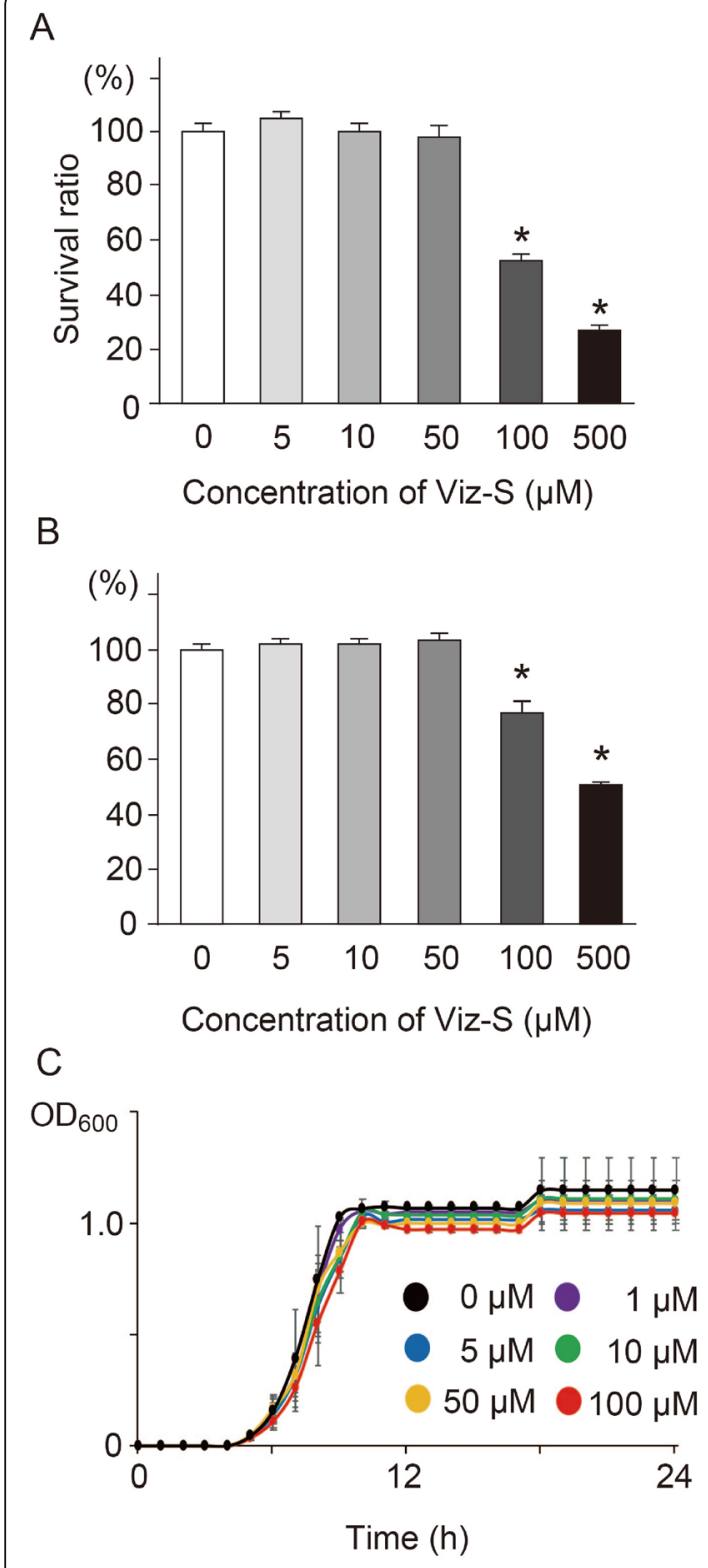

D

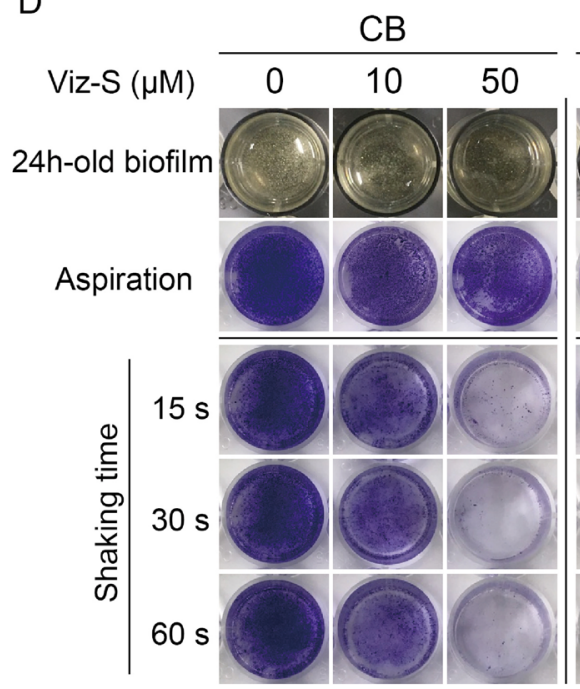

$$
\text { E }
$$

$\mathrm{CB}$

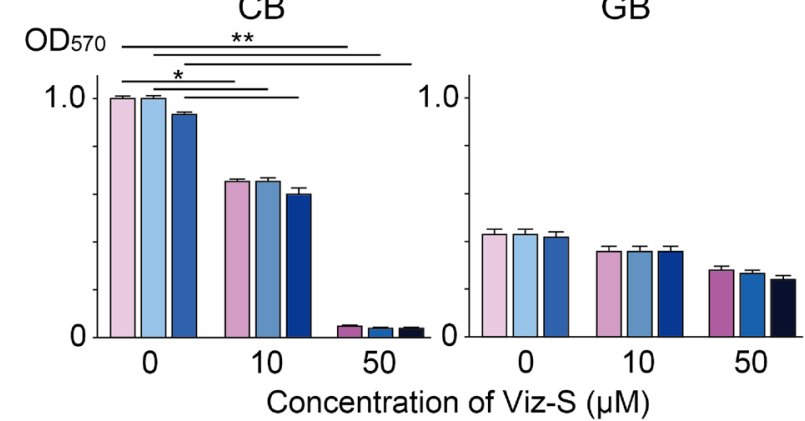

Shaking time: $\square \square \square 10 \mathrm{~s} \quad \square \square \square 30 \mathrm{~s} \quad \square \square \square 0 \mathrm{~s}$

$\mathrm{F}$

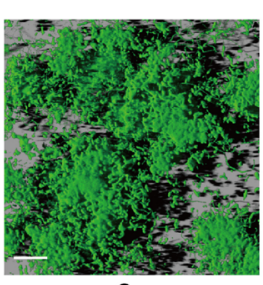

0

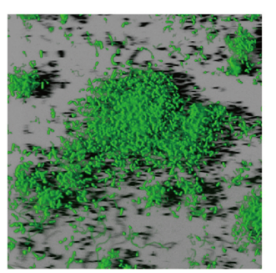

10

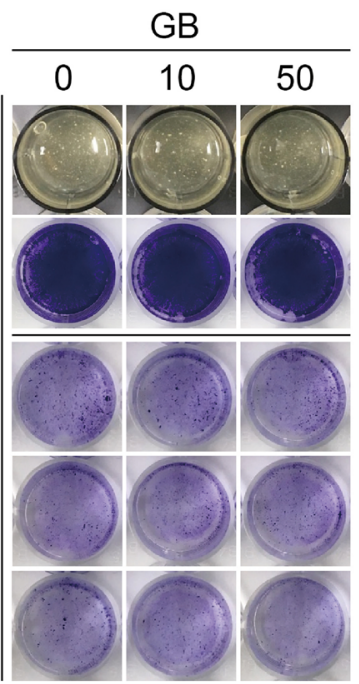

$\mathrm{GB}$

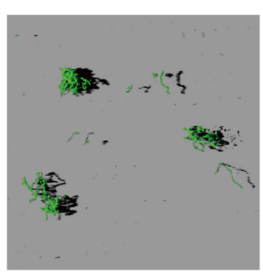

50

Concentration of Viz-S $(\mu \mathrm{M})$

Fig. 1 Cytotoxicity of Viz-S in (a) human gingival epithelial cells (HGECs) and (b) human gingival fibroblasts (HGFs). Cells were incubated in MEM or DMEM containing Viz-S for $3 \mathrm{~h}$ at $37^{\circ} \mathrm{C}$. The cellular viability was assessed using an MTT assay $(n=6) .{ }^{*} p<0.01$, as compared with the control group. c Growth curves of bacteria derived from human saliva in the presence or absence of Viz-S $(n=4)$. There were no significant growth differences among the concentrations of Viz-S $(p>0.05)$. $\mathbf{d}$ Residual biovolumes following shaking motion for 15,30 and $60 \mathrm{~s}(n=5)$. The remaining structure was stained with $0.1 \%$ crystal violet. A $24 \mathrm{~h}$-old biofilm: Photographs of the biofilm structure after a 24-h incubation.

Aspiration: The structure after the supernatant was removed without a washing procedure. e Total biomass determined by measuring absorbance at $570 \mathrm{~nm}(n=5) .{ }^{* *} p<0.01,{ }^{*} p<0.05$, compared with the control group. $\mathbf{f}$ Three-dimensional reconstruction images of residual CB stained with a fluorescent bacterial viability kit following shaking motion for $15 \mathrm{~s}(n=3)$. Live bacteria appear fluorescent green (SYTO9) and dead bacteria appear fluorescent red (PI). Scale bar $=30 \mu \mathrm{m}$

\section{Differentiating composition of cariogenic and gingivitis biofilms}

The microbial compositions of the human saliva biofilms cultured with different nutrient sources, were analyzed by $16 \mathrm{~S}$ rRNA sequencing. Firmicutes was the most prevalent phylum among all groups constituting $92 \%$ of
$\mathrm{CB}$ in the control group, $88 \%$ of $\mathrm{CB}$ in the $50 \mu \mathrm{M}$ group, $93 \%$ of GB in the control group, and $94 \%$ of GB in the $50 \mu \mathrm{M}$ group $(p>0.05)$. At the genus level, 69 genera in total were detected and 15 genera of these existed at a rate of $>0.1 \%$. $16 \mathrm{~S}$ sequencing of $\mathrm{CBs}$ and GBs revealed no significant differences in their richness (Fig. 2a). The 
Table 1 Quantitative analysis of the protein and carbohydrate compositions

\begin{tabular}{llllll}
\hline $\begin{array}{l}\text { Concentration } \\
\text { of Viz-S }\end{array}$ & CB & & GB & \\
\cline { 2 - 5 } \cline { 5 - 6 } & Protein & Carbohydrate & & Protein & $27.4 \pm 2.9$ \\
\hline 0 & $336.4 \pm 6.2$ & $48.7 \pm 2.1$ & $169.9 \pm 16.0$ & $28.1 \pm 2.5$ \\
10 & $364.7 \pm 8.4$ & $54.7 \pm 1.9$ & $165.3 \pm 25.0$ & $30.5 \pm 0.9$ \\
\hline 0 & $382.7 \pm 8.1$ & $58.9 \pm 2.5$ & $192.9 \pm 31.2$ & \\
\hline
\end{tabular}

Values are presented as mean \pm SEM $(\mu \mathrm{g})$ per well of five replicates. There was no significant difference between the control group and experimental group $(p>0.05)$

Shannon diversity index of the $\mathrm{CB}$ in the control group $(2.67 \pm 0.22)$ and $\mathrm{CB}$ in the $50 \mu \mathrm{M}$ group $(2.63 \pm 0.15)$ were significantly lower than those of the GB in the control group $(3.52 \pm 0.35)$ and $\mathrm{GB}$ in the $50 \mu \mathrm{M}$ group $(3.59 \pm 0.34)(p<0.05)$, indicating that the composition of the $\mathrm{CB}$ was less diverse than that of the GB. However, the addition of Viz-S did not influence the diversity of the biofilm $(p>0.05)$. Principal component analysis showed that individual CBs were clearly separated from GB derived from pooled saliva with or without Viz-S (Fig. 2b). Beta diversity did not differ between the $\mathrm{CB}$ in the control group and $\mathrm{CB}$ in the $50 \mu \mathrm{M}$ group $(p=0.33)$. LefSe analysis also showed no significant differences in the OTUs at the genus level between the control and $50 \mu \mathrm{M}$ Viz-S groups. Principal component analysis of individual GBs is shown in Fig. S1.

At the genus level, the most abundant OTU in the $\mathrm{CB}$ derived from the pooled saliva (control) was Streptococcus $(89.1 \% ; 29,882$ reads), followed by Rothia $(3.9 \% ; 1308$ reads) (Fig. 2c). Similarly, the CB with $50 \mu \mathrm{M}$ Viz-S presented Streptococcus $(83.6 \% ; 31,862$ reads) as the most abundant followed by Rothia (5.5\%; 2096 reads). The Streptococcus and Veillonella genera were the most dominant in the GB derived from the pooled saliva (control), each accounting for $48.5 \%$ (11,578 reads) and $39.0 \%$ (9310 reads) of the sequences, respectively. GB in the presence of $50 \mu \mathrm{M} \mathrm{Viz-S}$ revealed that Streptococcus (42.0\%; 10,385 reads) was the most abundant, followed by Veillonella (45.4\%; 11,226 reads).

q-PCR analysis of bacterial strains in the $\mathrm{CB}$ for the control group showed that Streptococcus salivarius was the most abundant species (30\%) followed by S. oralis (18\%), S. sanguinis (18\%), S. gordonii (10\%), S. mitis (8\%), and S. mutans (2\%). The bacterial flora in the CB developed in the presence of $50 \mu \mathrm{M} \mathrm{Viz}-\mathrm{S}$ had a similar bacterial composition as those in the CB control, revealing $28 \%$ for S. salivarius, followed by S. oralis (18\%), S. sanguinis (16\%), S. gordonii (12\%), S. mitis (10\%), and S. mutans (2\%). S. sobrinus was not detected from the pooled saliva sample as well as the CBs.

q-PCR analysis of bacterial strains in the GB for the control group showed that $S$. sanguinis was the most abundant species (25\%), followed by S. salivarius (22\%), S. oralis (12\%), S. mitis (12\%), and S. gordonii (8\%). The bacterial flora in the GB developed in the presence of
$50 \mu \mathrm{M}$ Viz-S had a similar bacterial composition as those in the GB control, revealing $23 \%$ for S. sanguinis, followed by S. salivarius (18\%), S. oralis (16\%), S. mitis (12\%), and S. gordonii (10\%). S. mutans and S. sobrinus were not detected from both the control and $50 \mu \mathrm{M} \mathrm{Viz-}$ $S$ group.

To clarify the mechanism for enhanced disruption in the $\mathrm{CB}$ containing $50 \mu \mathrm{M}$ of $\mathrm{Viz}-\mathrm{S}$, further analyses were focused on gene expression changes in the genus Streptococcus.

\section{Expression analysis of genes associated with biofilm formation in $\mathrm{CB}$ and $\mathrm{GB}$}

The expression profiles of fifteen genes in genus Streptococcus assumed to participate in the formation of $\mathrm{CB}$ and $\mathrm{GB}$ after $24 \mathrm{~h}$ incubation are summarized in Fig. 3. In the $\mathrm{CB}$ containing $50 \mu \mathrm{M} \mathrm{Viz}-\mathrm{S}$, the transcription of several glucosyltransferase $(g t f)$ genes involved in the biosynthesis of water-soluble glucan, including $g t f K$ for $S$. salivarius, gtfP for S. sanguinis, gtfG for S. gordonii, and gtfD for $S$. mutans, were significantly downregulated (Fig. 3a, $p<$ $0.05)$. In contrast, the transcription of $g t f B$ and $g t f C$, associated with the synthesis of water-insoluble glucans in $S$. mutans, was significantly upregulated compared to those in the control group $(p<0.01)$. There were also significant differences between the control and the $10 \mu \mathrm{M}$ group in the transcription of $g t f B$ and $g t f C(p<0.05)$.

The expression of genes involved in the quorum sensing (QS) system, such as those encoding competence stimulating peptide (CSP)-ComDE [18] and LuxS [19], was also examined. The expression of $l u x S$ for three species in the $50 \mu \mathrm{M}$ group was significantly downregulated compared with those in the control group (Fig. 3b, $p<$ 0.05). comD and comE expression were found to depend on the bacterial species. The expression of comE for both $S$. oralis and S. mutans in the $50 \mu \mathrm{M}$ Viz-S group was significantly upregulated compared to that in the control group, whereas comE for S. sanguinis was significantly downregulated (Fig. 3b, $p<0.05$ ). The expression of comD for $S$. gordonii was not significantly changed in the presence of Viz-S.

Gene transcription in the GB containing $50 \mu \mathrm{M}$ Viz-S was similar to that of $\mathrm{CB}$ in the $50 \mu \mathrm{M}$ group, except comE for S. oralis and for S. mutans. All gene transcripts were downregulated or unchanged (Fig. 3c). 


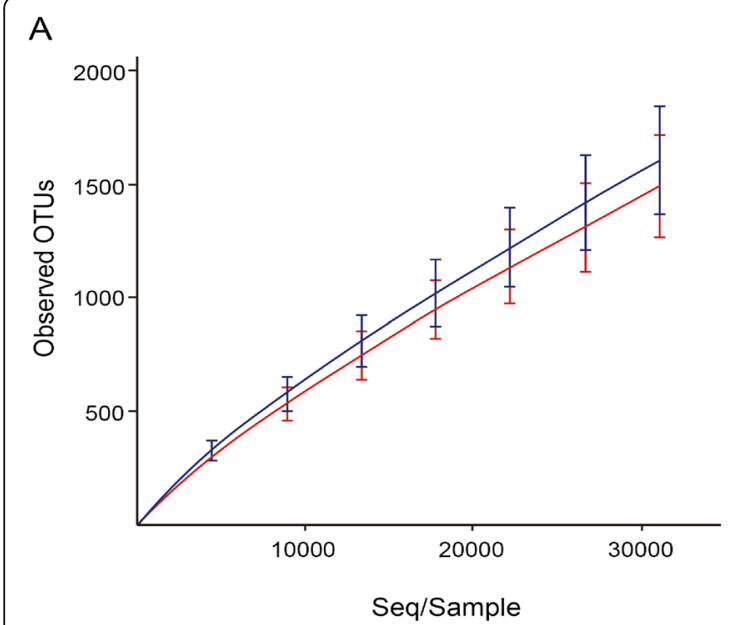
in the absence of Viz-S

$\mathrm{B}$ derived from five individual donors in the presence of $50 \mu \mathrm{M} \mathrm{Viz-S}$
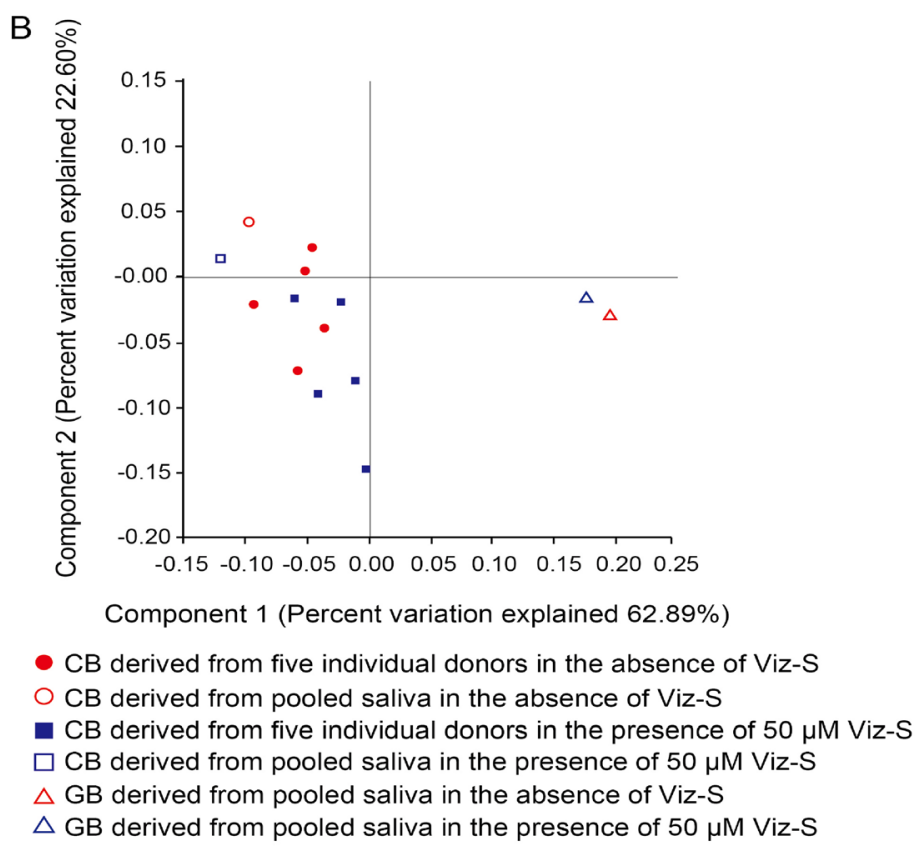

C
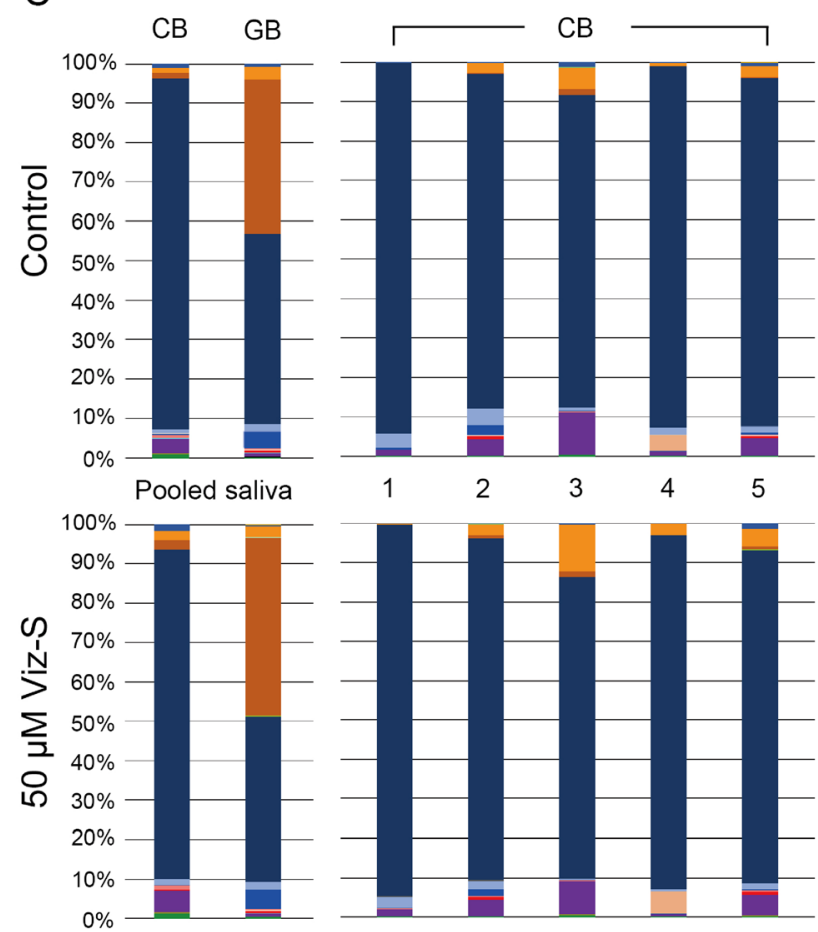
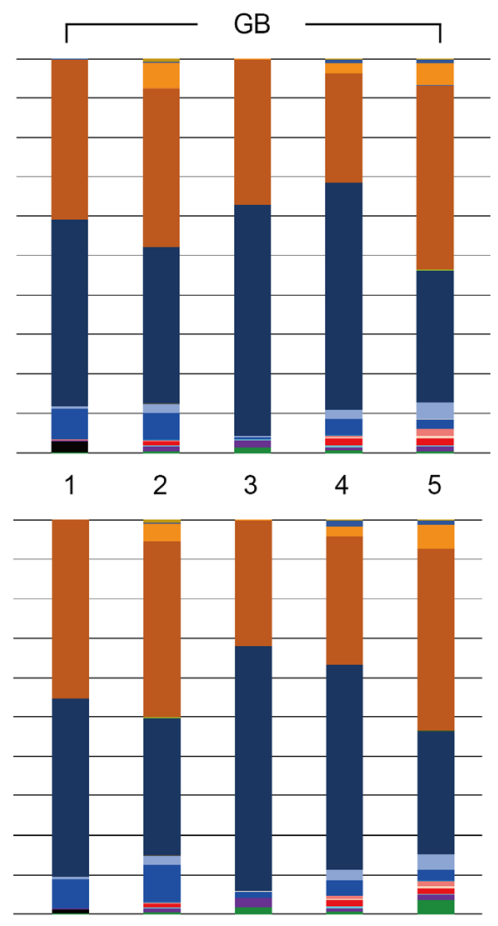

Capnocytophaga Neisseria

Porphyromonas Alloprevotella

Prevotella

Veillonella

Corynebacterium

Alloscardovia

Rothia

Actinomyces

Bulleidia

Atopobium

Gemella

Granulicatella

Streptococcus

Fig. 2 a Microbial richness in CB and GB in the absence and presence of $50 \mu \mathrm{M}$ Viz-S $(n=5)$. b Principal component analysis plot of CB and GB. c Relative abundance of major bacterial genera. Sequence data for determining the genera in the $C B$ and GB were obtained from 5 individual donors and the pooled saliva from these 5 donors

Expression analysis of genes associated with bacterial adhesion in streptococci

The expression profile of 28 genes assumed to participate in bacterial adherence following incubation for $4 \mathrm{~h}$ in the genus Streptococcus, is summarized in Fig. 4.
When the saliva mixture was incubated in $1 / 4$ strength BHI broth with $0.2 \%$ sucrose containing $50 \mu \mathrm{M}$ of Viz-S, the transcription of several $g t f$ genes involved in the biosynthesis of water-soluble glucan, including $g t f K$ in $S$. salivarius, gtfP in S. sanguinis, gtfG in S. gordonii, and 


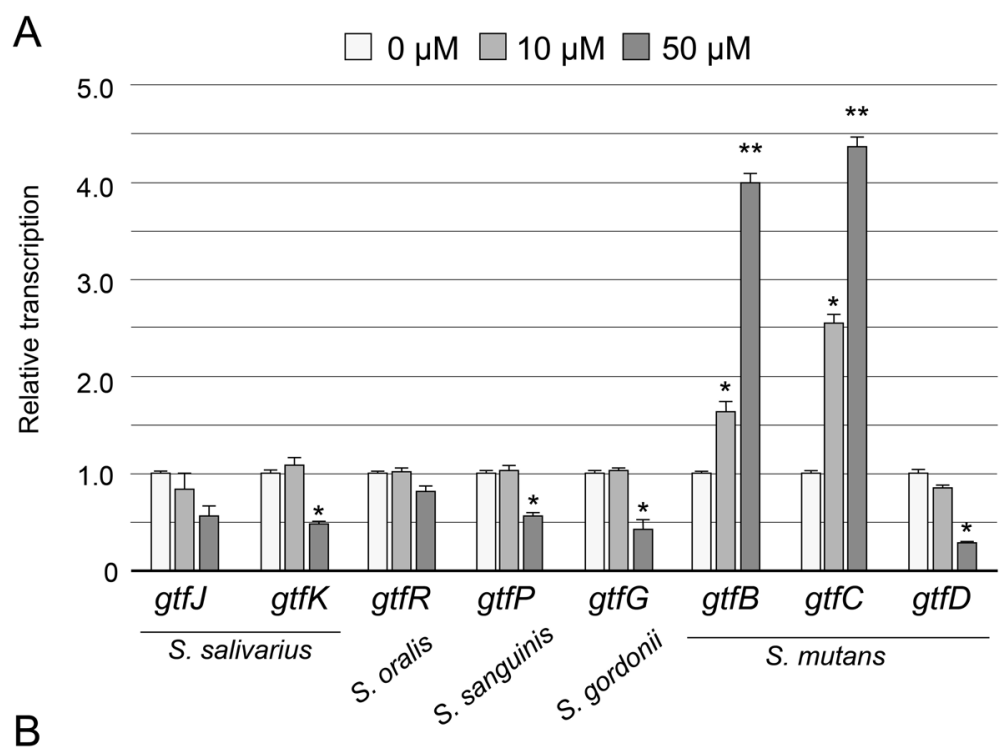

B

4.0

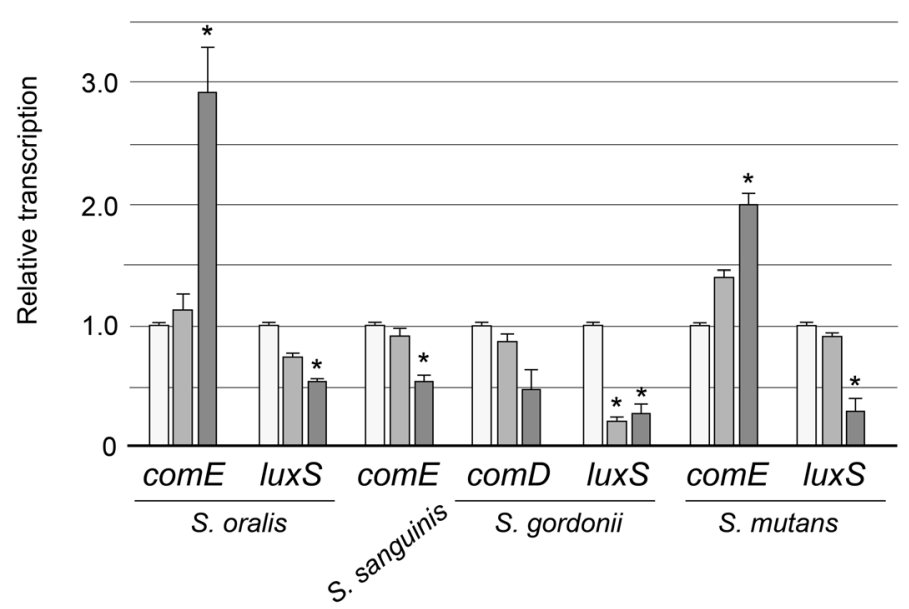

C

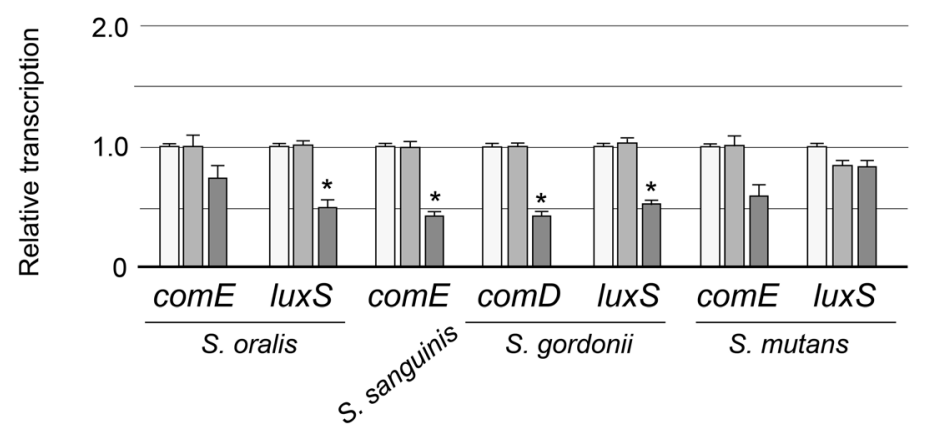

Fig. 3 Expression profiles of genes associated with biofilm formation in $C B$ and $G B(n=6)$. a gtf genes in $C B$, genes related to $Q S$ in $C B$ (b) and $\mathrm{GB}(\mathbf{c}) .{ }^{*} p<0.05,{ }^{* *} p<0.01$, compared with the control group

gtfD in S. mutans, was significantly downregulated (Fig. $4 \mathrm{a}, p<0.05)$. In contrast, the transcription of $g t f B$ and gtfC in $S$. mutans was significantly upregulated compared to that in the control group $(p<0.01)$. The expression of genes that encode surface antigens varied among the bacterial species (Fig. 4b). Transcription of $p s p C$ in $S$. mitis, $a b p A$ and $a b p B$ in S. gordonii, and $s r t A$ and spaP in $S$. mutans in the $50 \mu \mathrm{M}$ Viz-S group was 

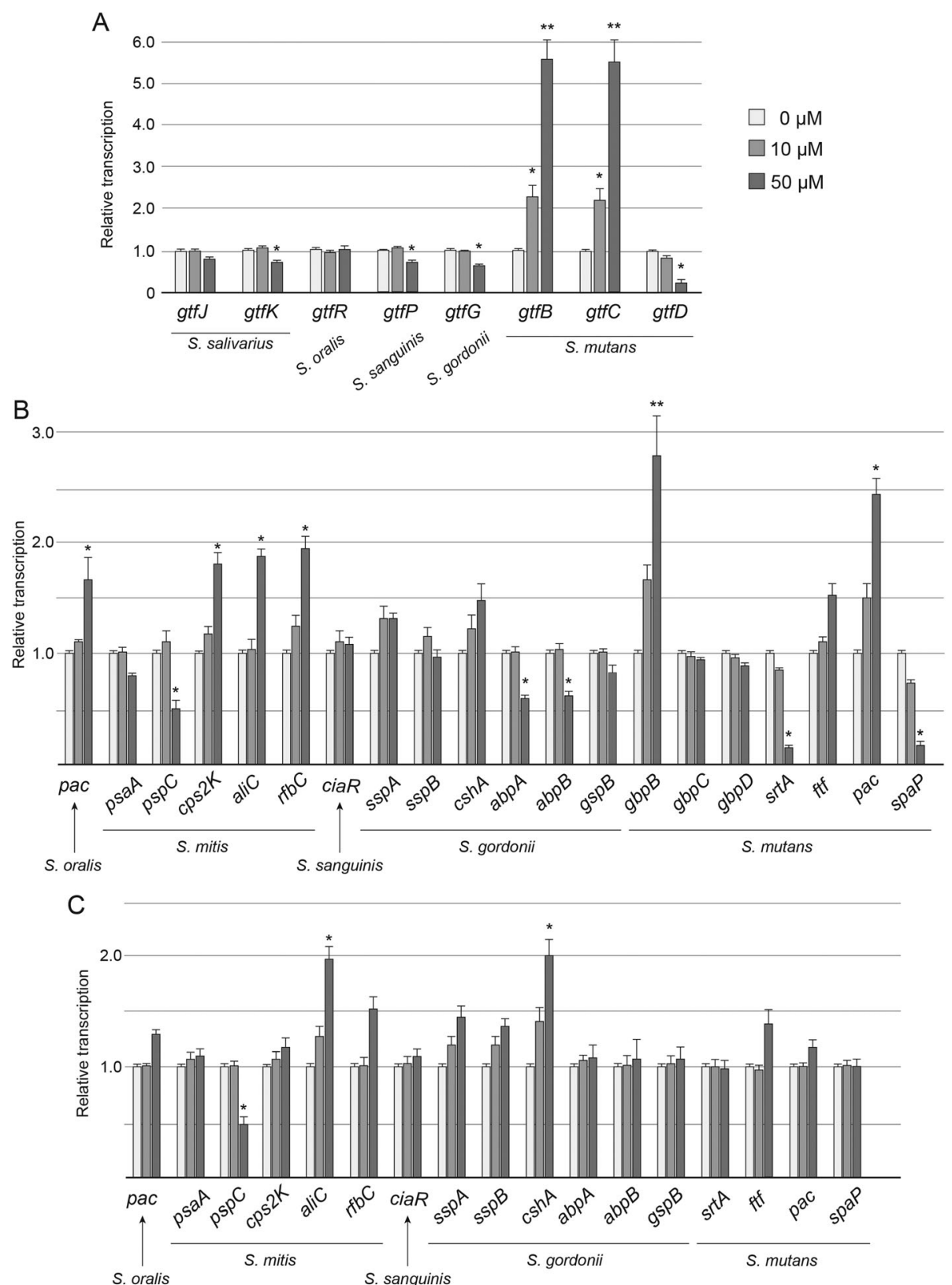

Fig. 4 Expression profiles of genes associated with bacterial adhesion $(n=6)$. Transcription of gtfs $(\mathbf{a})$ and genes related to surface antigens (b) in the genus Streptococcus when the saliva mixture was incubated in $1 / 4$ strength BHI broth with $0.2 \%$ sucrose. c Transcription of genes related to surface antigen in the genus Streptococcus when the saliva mixture was incubated in $1 / 4$ strength BHI broth with $10 \%$ FBS. ${ }^{*} p<0.05$, **p $p 0.01$, compared with the control group

also significantly downregulated compared with that in the control group $(p<0.05)$. In contrast, the transcription of both pac in $S$. mutans and a gene encoding the PAc protein homolog [20] in S. oralis were significantly upregulated when $50 \mu \mathrm{M}$ of Viz-S was included in the media. The transcription of $\operatorname{cps} 2 K$, aliC, and $r f b C$ in $S$. mitis and glucan-binding protein B $(g b p B)$ in $S$. mutans in the $50 \mu \mathrm{M}$ Viz-S group were also significantly upregulated compared with those in the control group.
When the saliva mixture was incubated in $1 / 4$ strength BHI broth with $10 \%$ FBS containing $50 \mu \mathrm{M}$ of Viz-S, the transcription of most genes remained unchanged except for $p s p C$ and aliC in S. mitis and cshA in S. gordonii (Fig. 4c).

\section{Binding of vizantin on bacteria and altered hydrophobic property}

Almost all successfully attached bacteria on the glass bottom during first two hours were cocci (Fig. 5a). Fluo- 

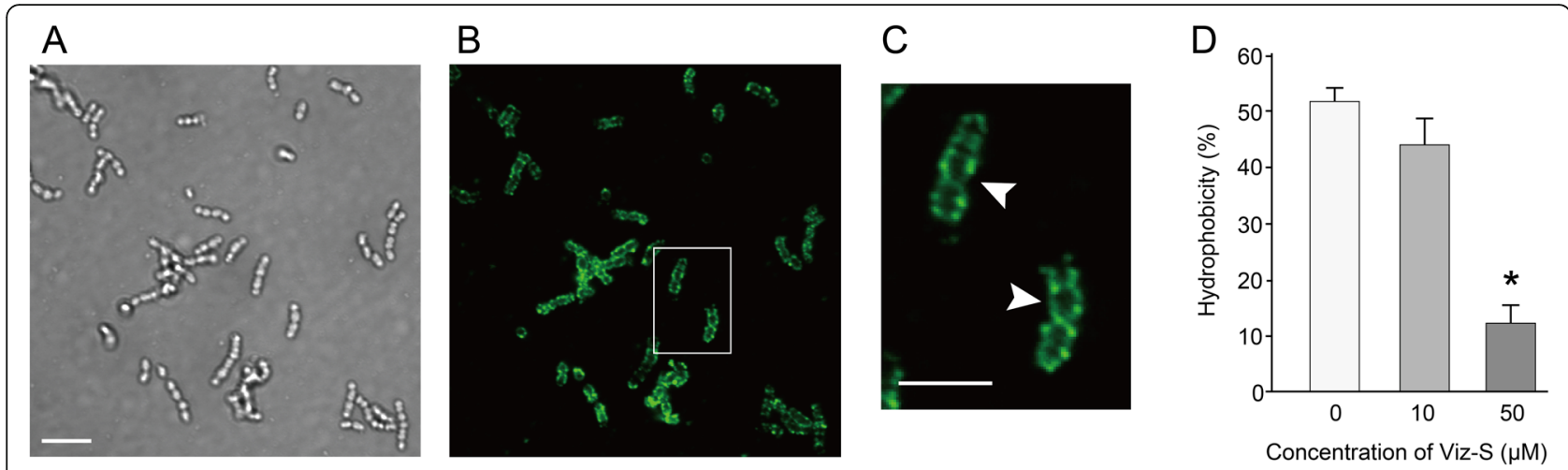

Fig. 5 a-c Representative image of localization of Bodipy-labelled vizantin (Fluo-Viz) on the cell surface. a Transmission image of glass bottom surface. Almost all adhered cells were cocci (An additional zoom of $3 \times$ using a 100x oil-immersion objective lens). Scale bar $=5 \mu \mathrm{m}$. $\mathbf{b}$ Fluorescence image. Fluo-Viz (green) bound to the bacterial surface. c Higher magnification of the area indicated by the squares in B (an additional zoom of $5 \times$ ). Arrowheads show the chains of Streptococci. Scale bar $=5 \mu \mathrm{m}$. $\mathbf{d}$ Hydrophobic property determined using microbial adhesion to hydrocarbon (MATH) test following exposure to 10 or $50 \mu \mathrm{M}$ of Viz-S for $10 \mathrm{~min}(n=6)$. ${ }^{*} p<0.05$, compared with the control

Viz bound to the cell surface of the bacteria, demonstrating chains of Streptococci (Fig. 5b, c). The microbial adhesion to hydrocarbon (MATH) test showed that Viz$S$ interacted with the surfaces of the microorganisms in saliva and rendered them more hydrophilic. Cells treated with the $50 \mu \mathrm{M}$ concentration of Viz-S showed that hydrophobicity was reduced to one-fourth in the untreated cells $(p<0.05$, Fig. 5 d).

\section{Bacterial adhesion to a hydroxyapatite disc following exposure to Viz-S}

The number of microorganisms adhering to the hydroxyapatite surface in the bacterial adhesion assay were decreased significantly when the bacteria were exposed to $50 \mu \mathrm{M}$ of Viz-S for $10 \mathrm{~min}$. The mean number (Mean \pm SEM) of viable microorganisms that had attached in 20 min was $4.49 \pm 0.05$ for the control and $3.70 \pm 0.09$ for the $50 \mu \mathrm{M}$ group, showing a significant difference between the control and $50 \mu \mathrm{M}$ groups $(p<0.05)$.

\section{Discussion}

In this study, we demonstrated that Viz-S at a concentration of $50 \mu \mathrm{M}$ caused detachment of the biofilm composed mainly of the genus Streptococcus despite supplementation with sucrose as a nutrient source. We found that $50 \mu \mathrm{M}$ of Viz-S did not affect the bacterial growth and viability; additionally, microbiome analysis revealed that $50 \mu \mathrm{M}$ of Viz-S did not alter the bacterial composition in $\mathrm{CB}$ under the culture conditions used in this study. In developing antibiofilm strategy using a chemical compound, preserving a balanced microbiome is one of the critical factors to be considered. Disruption of equilibrium in the oral ecosystem creates a dysbiosis either by overgrowth of specific microorganisms or by changes in the local host response where the community can support a disease state [6, 21].
Viz-S at less than $50 \mu \mathrm{M}$ did not demonstrate cytotoxicity in HGECs and HGFs (Fig. 1a and b). We also performed a cytokine assay to determine whether Viz-S stimulated the production of inflammatory cytokines in HGECs and human monocyte/macrophage (THP-1) cells. The results showed that the levels of interleukin-1 beta (IL-1 $\beta$ ), tumor necrosis factor (TNF), and interleukin8 (IL-8) in both HGECs (data not shown) and THP-1 following $50 \mu \mathrm{M}$ of Viz-S treatment did not increase (Fig. S2). These results indicate that Viz-S may be a candidate detachment-promoting agent against early colonizing bacteria (mainly Streptococcus) while preserving resident microflora.

The influence of Viz-S on the GB remains unclear because GB showed a reduced volume after 15-s agitation regardless of Viz-S (Fig. 1d). Veillonella, the second most abundant genus in GB, act as bridging species to support the colonization and growth of later colonizers including Porphyromonas gingivalis rather than in biofilm formation [22]. Many kinds of Veillonella species such as $V$. denticariosi, $V$. parvula, $V$. rogosae, $V$. atypica, $V$. dispar, and $V$. tobetsuensis were detected in GB (Fig. S3).

Some agents or molecules have been reported to enable detachment or degradation of oral biofilms [23-26]. However, some of these candidate substances target a specific species or substance. Viz-S seemed to be effective at least for the genus Streptococcus.

Considering that the biofilm composed mainly of the genus Streptococcus was detached by $50 \mu \mathrm{M}$ Viz-S in the presence of sucrose, we hypothesized that Viz-S caused detachment of the biofilm through modulation of the sucrose-dependent metabolic activities in Streptococcus species. Gene expression analysis in CB showed downregulation of $g t f s$ involved in the biosynthesis of watersoluble glucan in the genus Streptococcus (Fig. 3a, 4a). 
Downregulation of water-soluble glucan may weaken cohesion among bacteria. Water-soluble glucan is also reported to play an important role in biofilm formation. Yoshida et al. demonstrated that gtfP-deficient S. sanguinis exhibits a marked reduction in the amount of watersoluble glucans in the culture supernatant, and produces decreased amounts of extracellular polymeric substances compared to the wild-type [27]. S. gordonii, an important pioneer colonizer, has a gtfG that synthesizes both $\alpha 1.3$ and $\alpha 1.6$-linked glucans [28]. GTFG is reported to influence biofilm interactions with other bacterial species such as Candida albicans [29]. In S. mutans, the expression of $g t f D$, which synthesizes water-soluble glucans, was significantly downregulated in the $50 \mu \mathrm{M}$ group. However, the expression of $g t f B$ and $g t f C$ was significantly upregulated by more than 4.0-fold (Fig. 3a, 4a). Previous studies have reported that the presence of all three Gtfs at an optimal ratio is necessary for the biofilm stability [30, 31]. For example, Ooshima et al. reported that the highest level of sucrose-dependent adherence was attained when GtfB, GtfC, and GtfD were present at a ratio of 20:1:4 [31]. Matsumoto et al. reported that binding of the soluble glucan synthesized by GtfD to GbpC protein enhanced the sucrose-dependent adhesion [32].

Of the two QS systems in the genus Streptococcus, the expression of luxS in S. oralis, S. gordonii, and S. mutans was significantly downregulated in the $50 \mu \mathrm{M}$ Viz-S groups (Fig. 3b). The pathway of autoinducer-2 (AI-2) synthesized by luxS can control the expression of genes involved in a variety of metabolic pathways and pathogenic mechanisms. The phenomenon of significant biofilm detachment from the basal surface can be explained to some extent. McNab et al. demonstrated that the inactivation of S. gordonii luxS downregulated the expression of gtfG [33]. Cuadra-Saenz et al. reported that a dual-species luxS mutant biofilm by $S$. oralis and S. gordonii had a bigger volume and sparser architecture compared with that formed by the wild-type pair [34]. Yoshida et al. reported that biofilm formation by the luxS mutant of S. mutans in $0.5 \%$ sucrose defined medium was markedly attenuated compared to that of the wild type, and the gtfB and gtfC genes, but not the gtfD gene, were upregulated in the mid-log growth phase [19]. In addition, the luxS mutant exclusively formed very large clumps compared to the biofilm formed by the wild type and its structure was easily detached by washing. Further, the hydrophobicity of the luxS mutant strain was lower than that of the wild-type strain [35], suggesting that the adhesion property was likely to decrease. From these findings, downregulation of $\operatorname{luxS}$ expression may alter the biofilm structure that tends to be dispersed easily.

Oral streptococci express multiple adhesins that enable them to adhere to human teeth and aggregate with each other. Among a limited number of adherenceassociated genes analyzed in this study, only five of twenty genes were significantly downregulated (Fig. 4b). The downregulation of these genes may influence bacterial adhesion. For example, S. gordonii produces two amylase binding proteins: amylase binding protein A (AbpA) and AbpB. AbpA acts as the major receptor of salivary amylase binding to the bacterial surface [36]. AbpA-deficient strains show decreased adherence to amylase-coated hydroxyapatite [37]. Downregulation of $a b p A$ and $a b p B$ may thus contribute to the attenuated adhesion. In $S$. mutans containing $50 \mu \mathrm{M}$ Viz-S, the expression of $\operatorname{srtA}$ (sortase A) and spaP (surface protein), which are associated with non-sucrose metabolism, were significantly downregulated compared with those in the control group. In contrast, the expression of pac (cell surface protein antigen c) was significantly upregulated. PAc is known to participate in bacterial adherence to teeth via interaction with the salivary pellicle [38]. Further, the expression of a gene in $S$. oralis that encodes an amino acid sequence with $76.2 \%$ similarity to the PAc protein precursor of $S$. mutans and $73.8 \%$ homology with the SpaA protein precursor of S. sobrinus [20], was significantly upregulated. It is unclear how the expression of these genes contributes to bacterial adhesion. As a variety of microorganism surface proteins are assumed to be involved with bacterial adhesion, the whole mechanism of biofilm detachment caused by Viz-S remains unclear.

To investigate whether Viz-S prevents bacterial attachment non-specifically, MATH test and bacterial adhesion assay were also performed. The bacteria bound to Viz-S showed decreased hydrophobicity (Fig. 5d) and inhibited bacterial adhesion. Thus, Viz-S binding affects bacterial adhesion non-specifically, and may also influence cell-to-cell and cell-to-host interactions.

Although we have found some clues to elucidate the mechanism associated with Viz-S activity, further investigations are needed to demonstrate how the transcriptional changes induced by $\mathrm{Viz}-\mathrm{S}$ contribute to promote biofilm detachment at the protein level.

\section{Conclusions}

Numerous and diverse microorganisms reside in our intraoral environment, and we all coexist with oral biofilms. Thus, using a chemical antibiofilm strategy in the oral cavity would be different from the approaches used against medical pathogens elsewhere in the body. The aim for chemical control would be to prevent biofilm accumulation rather than eradication, while still preserving the benefits of the normal resident oral microflora.

In this study, Viz-S showed the ability to detach biofilms composed mainly of the genus Streptococcus through two possible mechanisms. As a specific reaction, 
Viz-S affects the expression of genes associated with bacterial adhesion and biofilm formation in Streptococcus species. Reduced structural stability might facilitate the detachment of these biofilms. As a non-specific reaction, Viz-S reduces bacterial adherence by changing the surface property of cells, without affecting bacterial growth or causing cytotoxicity. However, these mechanisms remain undetermined, and the efficacy against periodontal pathogens is necessary to elucidate by further analyses.

Within the limitations of this in vitro study, it was demonstrated that Viz-S may be a candidate for a new antibiofilm strategy targeting the biofilm matrix while preserving the resident microflora. Further clinical studies are needed to evaluate the impact of Viz-S for the control of oral biofilms.

\section{Methods}

\section{Cellular toxicity of sulfated vizantin}

Viz-S was prepared as described in a previous report [39]. HGECs (Ca9-22; RIKEN BioResource Center, Ibaraki, Japan) and HGFs (ATCC PCS-201-018; Summit Pharmaceuticals International, Tokyo, Japan) were grown to $90 \%$ confluence in minimum essential medium (MEM; Life Technologies, Grand Island, NY, USA) or Dulbecco's modified Eagle's medium (DMEM; Wako Pure Chemical Industries, Osaka, Japan) containing 10\% fetal bovine serum (FBS) (Japan Bio Serum, Hiroshima, Japan) and $1 \%$ penicillin-streptomycin (Wako Pure Chemical Industries) at $37^{\circ} \mathrm{C}$ in $5 \% \mathrm{CO}_{2}$. The cells were then seeded at a density of $1 \times 10^{5}$ cells $/ \mathrm{ml}$ in MEM or DMEM to 96-well plates. The cells were then incubated in the presence of Viz-S at concentrations of 0, 5, 10, 50, 100 , and $500 \mu \mathrm{M}$ for $3 \mathrm{~h}$ at $37^{\circ} \mathrm{C}$. Cellular viability was assessed using a methyl thiazolyl tetrazolium (MTT) assay [40], performed with a total of six replicates per treatment.

\section{Saliva collection}

Unstimulated saliva was collected from five healthy volunteers. Informed consent was obtained from all participating subjects under a protocol reviewed and approved by the Niigata University Ethics Committee (25-R16-0815). The donors abstained from food and drink intake for $2 \mathrm{~h}$ prior to saliva donation. The saliva was diluted twofold with sterile $60 \%$ glycerol and was stored at $80^{\circ} \mathrm{C}$ until used [41]. The same volume of saliva samples was pooled in a tube immediately before use, and a single pooled sample was used as bacterial inoculation for biofilm preparation [42, 43].

\section{Growth curve assay}

Pooled saliva ( $40 \mu \mathrm{l})$ was added to $2 \mathrm{ml}$ of brain heart infusion (BHI) broth (Difco Laboratories, Detroit, MI,
USA) using a 24-well tissue culture plate (Falcon ${ }^{\mathrm{Tx}}$, Fisher Scientific, Waltham, MA, USA) containing 0, 5, 10,50 , and $100 \mu \mathrm{M}$ of Viz-S. The plate was statically incubated at $37^{\circ} \mathrm{C}$ under anaerobic conditions. The $\mathrm{OD}_{600}$ was recorded at hourly intervals. A growth curve assay was performed with a total of four replicates per treatment.

\section{Detachment property of Viz-S in CB and GB}

Two distinct oral biofilms, namely cariogenic and gingivitis biofilms, derived from healthy human saliva, were used as described previously, with a slight modification $[42,43]$. The media used were $1 / 4$ strength BHI broth with $0.2 \%$ sucrose for the cariogenic biofilm $(\mathrm{CB})$, and $1 /$ 4 strength $\mathrm{BHI}$ broth with $10 \%$ fetal bovine serum for the gingivitis biofilm (GB). A 24-well plate was coated with $10 \%$ sterile saliva solution prepared, as described previously [44], for $2 \mathrm{~h}$ prior to the incubation (pellicle formation). Then, $40 \mu \mathrm{l}$ of a single pooled sample from five donors was used to inoculate the two types of media to form biofilms. The $\mathrm{CB}$ and $\mathrm{GB}$ were developed in a 24-well plate containing Viz-S at concentrations of 0, 10, and $50 \mu \mathrm{M}$ for $24 \mathrm{~h}$ at $37^{\circ} \mathrm{C}$ under anaerobic conditions.

After $24 \mathrm{~h}$, the medium in the wells was replaced with phosphate-buffered saline (PBS), without agitation. The biofilms were rotated at $500 \mathrm{rpm}$ for 15,30 , and $60 \mathrm{~s}$ at $37^{\circ} \mathrm{C}$ using a Thermo-Shaker (MyBL-P25, AS ONE, Osaka, Japan). The residual biofilms were stained with $0.1 \%$ crystal violet $(\mathrm{CV})$ for $15 \mathrm{~min}$. The wells were washed three times with PBS to remove the unbound $\mathrm{CV}$ and dried for $2 \mathrm{~h}$ at $37^{\circ} \mathrm{C}$. The bound $\mathrm{CV}$ was collected by adding $1 \mathrm{ml}$ of $30 \%(\mathrm{v} / \mathrm{v})$ acetic acid for $5 \mathrm{~min}$, and the total biomass was determined by measuring the absorbance at $570 \mathrm{~nm}$ with a colorimeter $\left(\mathrm{CO}^{\circ} 500^{\circ}\right.$, Funakoshi Co. Ltd., Tokyo, Japan) [17].

Morphological observation of the remaining structure in the $\mathrm{CB}$ group following a shaking motion for $15 \mathrm{~s}$ was performed using confocal laser scanning microscopy analysis. The residual structure was stained with a fluorescent bacterial viability kit (LIVE/DEAD ${ }^{\circ}$ BacLight $^{\text {tm }}$ Bacterial Viability Kit) (Thermo Fisher Scientific, Waltham, MA, USA) for $30 \mathrm{~min}$ at room temperature in the dark. The biofilm was imaged using a confocal laser scanning microscope with $\mathrm{Ar}$ 488-nm and He-Ne 543$\mathrm{nm}$ lasers (CLSM; FluoView ${ }^{\text {mat }}$ 300, Olympus, Tokyo, Japan). The filters were set to $510-530 \mathrm{~nm}$ for detection of the SYTO 9 stain, and to $>610 \mathrm{~nm}$ for propidium iodide (PI). A water-immersion objective lens $(\times 60)$ was used. Stacks of the fluorescence images were collected every $0.45 \mu \mathrm{m}$ in the $\mathrm{Z}$ dimension, and threedimensional reconstruction was carried out using Imaris ${ }^{\circ}$ software (Bitplane AG, Zurich, Switzerland) [17]. This assay was performed with a total of three replicates per treatment. 


\section{Quantitative analysis of protein and carbohydrate composition}

$\mathrm{CB}$ and $\mathrm{GB}$ were developed in the absence and presence of Viz-S for $24 \mathrm{~h}$, as described previously, in a 6-well plate. The supernatant was aspirated and the biofilm was washed twice except for $\mathrm{CB}$ in the $50 \mu \mathrm{M}$ Viz-S group, as the biofilm developed in the presence of $50 \mu \mathrm{M}$ Viz-S detached readily from the surface by a washing step. The biofilms were collected using a cell scraper (TPP Techno Plastic Products AG, Trasadingen, Switzerland). The collected biofilm was washed twice with PBS. The bacterial suspension was mechanically pulverized with Lysing Matrix B (MP Biomedical, Santa Ana, CA, USA) using a MagNA Lyser (Roche Diagnostic GmbH, Penzberg, Germany) at a speed of $7000 \mathrm{rpm}$ for $30 \mathrm{~s}$. The amount of protein in the biofilms was determined using a bicinchoninic acid (BCA) Protein Assay Kit (T9300A; Takara Bio Inc., Shiga, Japan) according to the manufacturer's instructions. After incubation for $30 \mathrm{~min}$, absorbance at $550 \mathrm{~nm}$ was measured using a colorimeter. The amount of carbohydrate in the biofilm was measured as described previously [12] with slight modification. Briefly, $500 \mu \mathrm{l}$ of a $5 \%$ aqueous solution of phenol was added to $500 \mu \mathrm{l}$ of supernatant, incubated for $20 \mathrm{~min}$, and then $2.5 \mathrm{ml}$ of concentrated sulfuric acid was added. The OD at $490 \mathrm{~nm}$ was measured using a colorimeter. This assay was performed with a total of five replicates per treatment.

\section{Microbiome analysis}

To determine the composition of biofilms cultured from the pooled sample in the absence and presence of $50 \mu \mathrm{M}$ Viz-S, genomic DNA was extracted using a NucleoSpin ${ }^{\odot}$ Microbial DNA (MACHEREY-NAGEL GmbH \& Co. KG, Duren, Germany) according to the manufacturer's instructions. The bacterial microbiota was investigated by targeted $16 \mathrm{~S}$ rRNA gene (V3-V4 region) sequencing using the Illumina MiSeq system $(2 \times 300 \mathrm{bp}$ paired-end reads) (Illumina, CA, USA) as described previously with some modification [45] (Bioengineering Lab. Co., Ltd., Kanagawa, Japan). Two-step polymerase chain reaction (PCR) procedures were performed to generate amplicon libraries. Ambiguous bases, low quality reads, and sequences with a read length below $200 \mathrm{bp}$ were discarded. The remaining sequences were clustered into phylotypes using QIIME with a minimum coverage of $99 \%$ and a minimum identity of $97 \%$. A representative sequence for each operational taxonomic unit (OTU) was selected for taxonomic assignment with reference to the EzBioCloud $16 \mathrm{~S}$ database. The protocols for amplicon libraries are summarized in Table S1.

The $\mathrm{CB}$ and $\mathrm{GB}$ derived from each individual saliva sample were also subjected to $16 \mathrm{~S}$ rRNA gene sequencing for bacterial diversity analysis. Alpha diversity was evaluated by the number of observed OTUs and the Shannon diversity index. Beta diversity was measured as the weighted UniFrac distance based on the OTU table and the difference between $\mathrm{CB}$ in the absence of Viz-S and that in the presence of $50 \mu \mathrm{M}$ was compared using a PERMANOVA. LEfSe, an algorithm for identifying the genomic taxa whose relative abundances differ significantly between two groups, was used for further analysis by a company (Bioengineering Lab. Co., Ltd.).

\section{Quantitative polymerase chain reaction (q-PCR) analysis}

To determine the species composition of the genus Streptococcus in the CB and GB, q-PCR analysis was performed as described previously [46-48]. Briefly, standard curves of representative species were first created. Serial 10-fold dilutions $\left(10^{4}-10^{9}\right.$ cells $\left./ \mathrm{ml}\right)$ of Streptococcus salivarius ATCC 27945, Streptococcus oralis ATCC 10557, Streptococcus mitis ATCC 49456, S. gordonii ATCC 10558, S. mutans UA159, and Streptococcus sanguinis ATCC 10556 in the logarithmic phase were prepared. Each genome DNA was extracted as described above, and q-PCR amplification was performed on the StepOnePlus real-time PCR system (Thermo Fisher Scientific) using the SYBR Green detection protocol according to the manufacturer's instructions. Species-specific primers for 16S rRNA genes are listed in Table S2. The primer sequences were obtained from those used in previous studies $[47,49]$ or were newly designed in this study. The genome sequences were retrieved from GenBank, and the real-time PCR primers were designed using Primer-BLAST. The primer specificity was checked using the BLAST tool on the NCBI website, and availability in the pooled saliva sample was confirmed by detecting the amplified product obtained by PCR. Each standard curve was generated by plotting the threshold cycle $\left(C_{T}\right)$ value against the known bacterial amount. $C B$ and $\mathrm{GB}$ developed for $24 \mathrm{~h}$ in a six-well plate were collected using a cell scraper, followed by genomic DNA extraction. The relative frequency of Streptococcus species was analyzed by q-PCR.

\section{Expression analysis of genes associated with biofilm formation in CB and GB cells by real-time PCR}

To investigate gene transcription associated with biofilm formation in the absence and presence of Viz-S, the $\mathrm{CB}$ and GB after $24 \mathrm{~h}$ were collected and washed twice with PBS. The bacterial pellet was resuspended in TRI Reagent (Molecular Research Center, Inc., Cincinnati, $\mathrm{OH}$, USA) and chemomechanically pulverized with Lysing Matrix B using a MagNA Lyser at a speed of $7000 \mathrm{rpm}$ for $30 \mathrm{~s}$. RNA isolation was performed using a Direct-zol RNA kit (Zymo Research, Irvine, CA, USA). The RNA was reverse transcribed using SuperScript VILO Master Mix (Thermo Fisher Scientific), and q-PCR with cDNA 
was performed on the StepOnePlus real-time PCR system using the SYBR Green detection protocol. The $16 \mathrm{~S}$ rRNA gene was used as an internal control for data normalization. The primers used in this study are listed in Table S3. The sequences of the primers were obtained from those used in previous studies [50-55] or were designed in this study. The primers were validated as previously described. This assay was performed with a total of six replicates per treatment.

\section{Expression analysis of adherence-associated genes in the $\mathrm{CB}$ and GB cells by real-time PCR}

To investigate gene transcription associated with bacterial adhesion in the absence and presence of Viz-S, $480 \mu \mathrm{l}$ of the saliva mixture was inoculated into $24 \mathrm{ml}$ of $1 / 4$ strength BHI broth with $0.2 \%$ sucrose or $1 / 4$ strength BHI broth with $10 \%$ FBS containing 0,10 , and $50 \mu \mathrm{M}$ of Viz-S in a centrifuge tube. The content was stirred at a speed of $150 \mathrm{rpm}$ at $37^{\circ} \mathrm{C}$ for $4 \mathrm{~h}$ under anaerobic conditions. $\mathrm{CB}$ and $\mathrm{GB}$ cells were collected by centrifugation ( $8000 \times g$ for $5 \mathrm{~min}$ ), washed thrice with PBS, and used for RNA extraction as described above. The RNA was reverse transcribed, and q-PCR was performed. The $16 \mathrm{~S}$ rRNA gene was used as an internal control for data normalization. The primers used in this study are listed in Table S4. The primer sequences were obtained from previous studies [53-60] or were newly designed in this study. The primers were validated as previously described. This assay was performed with a total of six replicates per treatment.

\section{Localization of vizantin in bacteria}

Bodipy-labeled vizantin (Fluo-Viz) was prepared according to a previously reported procedure for its synthesis [16]. The pooled saliva $(40 \mu \mathrm{l})$ was inoculated into $2 \mathrm{ml}$ of $1 / 4$ strength BHI broth with $0.2 \%$ sucrose using a glass bottom culture dish (MatTek Corp., Ashland, MA, USA) and incubated for $2 \mathrm{~h}$ at $37^{\circ} \mathrm{C}$ under anaerobic conditions. The adhered cells were washed twice with PBS; then, Fluo-Viz at a concentration of $50 \mu \mathrm{M}$ in distilled water was added to the dish, incubated for $45 \mathrm{~min}$ at $37^{\circ} \mathrm{C}$, washed twice with PBS, and imaged using a $488 \mathrm{~nm}$ laser line and a $510-530 \mathrm{~nm}$ band pass filter. An additional zoom of $3 \times$ or $5 \times$ was applied using a $100 \times$ oil-immersion objective lens.

\section{MATH test}

The saliva sample was incubated in BHI broth at $37^{\circ} \mathrm{C}$ under anaerobic conditions until mid-exponential growth. The bacterial culture was washed twice with PBS, centrifuged, and resuspended in PBS. The optical density of the sample was adjusted to 0.4 at $550 \mathrm{~nm}$ (OD1). The bacterial suspension was exposed to 0,10 , and $50 \mu \mathrm{M}$ of Viz-S with agitation for $10 \mathrm{~min}$ at $37^{\circ} \mathrm{C}$.
Then, $1 \mathrm{ml}$ of each treatment was mixed with $200 \mu \mathrm{l}$ of $n$-hexadecane. The mixtures were vortexed for $1 \mathrm{~min}$, and the phases were allowed to separate before the optical density of the aqueous phase was measured again (OD2). Hydrophobicity was calculated using the following equation: $\mathrm{MATH}(\%)=(\mathrm{OD} 1-\mathrm{OD} 2) / \mathrm{OD} 1 \times 100$ [61] . This assay was performed with a total of six replicates per treatment.

\section{Bacterial adhesion assay}

Hydroxyapatite (HA) discs measuring $6 \mathrm{~mm}$ in diameter and $1.5 \mathrm{~mm}$ in thickness (Olympus) were mounted in a flow-cell chamber (Convertible Flow Cell CFCAS0003, IBI Scientific, Dubuque, IA, USA). Two specimens were placed at either end so that their fluid flows did not interfere with each other. The chamber was sterilized using ethylene oxide gas for $4 \mathrm{~h}$. The flow-cell system comprised the bacterial suspension, a peristaltic pump, and a carboy for waste. These components were connected with silicone tubing (Fig. S4).

An adjusted saliva solution of $10 \mathrm{ml}$ was pumped into a chamber at a flow rate of $2 \mathrm{ml} / \mathrm{min}$ and kept static for $1 \mathrm{~h}$ at $37^{\circ} \mathrm{C}$ to allow salivary pellicle formation. The saliva was prepared as described above.

The optical density of the bacterial suspension derived from the pooled saliva in the logarithmic phase was adjusted to 0.025 at $600 \mathrm{~nm}$ in $1 / 4$ strength BHI broth with $0.2 \%$ sucrose. The suspension was exposed to $50 \mu \mathrm{M}$ of Viz-S with agitation for $10 \mathrm{~min}$ at $37^{\circ} \mathrm{C}$, followed by the connection to a flow-cell system, and pumping into the flow cell at a flow rate of $2 \mathrm{ml} / \mathrm{min}$ for $20 \mathrm{~min}$. Adhered bacteria were then collected and enumerated. The bacterial suspension without Viz-S exposure served as the control. A total of 10 discs were used per experimental condition.

\section{Statistical analysis}

Statistical analyses were performed using SPSS $^{\circ} 11.0$ (SPSS Inc., Chicago, IL, USA) and Excel Statistics 7.0 (Esumi Co., Ltd., Tokyo, Japan). Where applicable, the data are presented as the mean \pm standard error of the mean (SEM). Significance was determined using the Kruskal-Wallis test with a post hoc Steel-Dwass test (for the protein and carbohydrate compositions) or a post hoc Dunnett's test (for the cellular toxicity assay, crystal violet assay, MATH test, and gene expression analyses). Two-way analysis of variance was used to compare the bacterial growth test results. A paired Student's $t$-test was used to compare the bacterial adhesion test results.

Shannon diversity indices were compared with a oneway analysis of variance. PERMANOVA was performed on beta diversity. $P$ values $<0.05$ were considered to indicate statistical significance. 


\section{Supplementary Information}

The online version contains supplementary material available at https:/doi. org/10.1186/s12866-020-02033-w.

Additional file 1: CB structures after 24-h incubation containing Viz-S at concentrations of 0,50 and $100 \mu \mathrm{M}$.

Additional file 2: Fig. S1 Principal component analysis plot of $G B$ and CB.

Additional file 3:Fig. S2 Production of inflammatory cytokines in THP-1 cells following Viz-S treatment $(n=5)$. ${ }^{*} p<0.01$, compared with the control group (LPS).

Additional file 4: Fig. S3 Identification of Veillonella species using the polymerase chain reaction.

Additional file 5: Fig. S4 Flow-cell system used in this study.

Additional file 6: Table S1 Two-step PCR protocol used in this study.

Additional file 7: Table S2 165 rRNA primers used in this study.

Additional file 8: Table S3 Primer sequences used for analyzing the genes associated with biofilm formation by real-time PCR.

Additional file 9: Table S4 Primer sequences used for analyzing the genes associated with bacterial adhesion by real-time PCR.

\section{Abbreviations}

Viz-S: Sulfated vizantin; HGEC: Human gingival epithelial cell; HGF: Human gingival fibroblast; MEM: Minimum essential medium; DMEM: Dulbecco's modified Eagle medium; MTT: 3-(4,5-di-methylthiazol-2-yl)-2,5diphenyltetrazolium bromide, yellow tetrazole; $\mathrm{BHI}$ : Brain heart infusion; OD: Optical density; CB: Cariogenic biofilm; GB: Gingivitis biofilm; FBS: Fetal bovine serum; PBS: Phosphate-buffered saline; CV: Crystal violet; CLSM: Confocal laser scanning microscopy; PI: Propidium iodide; BCA: Bicinchoninic acid; OTU: Operational taxonomic unit; MATH: Microbial adhesion to hydrocarbon

\section{Acknowledgements}

We thank H. Yuasa and Y. Sato (Otsuka Chemical Co., Ltd., Tokushima, Japan) for supporting this research. We would like to thank Editage (www.editage. com) for English language editing.

\section{Authors' contributions}

All authors have read and approved the manuscript. Conception and design of the study: TH1, ST, MO, YN. Acquisition of data: TH1, ST, HD, TO, NH, YO, HY, HO, TH2, KS. Analysis: TH1, ST, MO, YT. Interpretation of data: TH1, ST, YT, YN. Drafting the article: TH1, ST. Revising the article critically for important intellectual content: $\mathrm{MO}, \mathrm{HD}, \mathrm{TO}, \mathrm{NH}, \mathrm{YO}, \mathrm{HY}, \mathrm{HO}, \mathrm{YT}$, YN. Funding acquisition: TH1, ST. Project administration: YN. Supervision: MO, YT, YN

\section{Funding}

This research was supported by JSPS KAKENHI grant numbers $19 \mathrm{H} 03958$ and 19 K24087. The funder had no role in study design, data collection and analysis, interpretation of data, and in writing the manuscript.

\section{Availability of data and materials}

All data are presented in the manuscript and supplemental figures. These data are available from the corresponding author upon reasonable request.

\section{Ethics approval and consent to participate}

The protocol of the present study was approved by the Niigata University Ethics Committee (25-R16-08-15). Written informed consent was obtained from all participating subjects prior to sample collection.

\section{Consent for publication}

Not applicable.

\section{Competing interests}

The authors declare that they have no competing interests.

\section{Author details}

'Division of Cariology, Operative Dentistry and Endodontics, Faculty of Dentistry \& Graduate School of Medical and Dental Sciences, Niigata University, 2-5274, Gakkocho-dori, Chuo-ku, Niigata 951-8514, Japan. ${ }^{2}$ Department of Microbiology and Infection Control Science, Kyoto Pharmaceutical University, Kyoto, Japan. ${ }^{3}$ Division of Microbiology and Infectious Diseases, Faculty of Dentistry \& Graduate School of Medical and Dental sciences, Niigata University, Niigata, Japan. ${ }^{4}$ Division of Periodontology, Faculty of Dentistry \& Graduate School of Medical and Dental sciences, Niigata University, Niigata, Japan. ${ }^{5}$ Faculty of Pharmaceutical Sciences, Tokushima Bunri University, Tokushima, Japan. ${ }^{6}$ Department of Chemistry and Functional Molecule, Faculty of Pharmaceutical Sciences, Tokushima Bunri University, Tokushima, Japan. ${ }^{7}$ Division of Anatomy and Cell Biology of Hard Tissue, Faculty of Dentistry \& Graduate School of Medical and Dental sciences, Niigata University, Niigata, Japan.

Received: 29 April 2020 Accepted: 3 November 2020

Published online: 25 November 2020

\section{References}

1. Kolenbrander PE, Palmer RJ Jr, Periasamy S, Jakubovics NS. Oral multispecies biofilm development and the key role of cell-cell distance. Nat Rev Microbiol. 2010;8:471-80.

2. Stewart PS, Franklin MJ. Physiological heterogeneity in biofilms. Nat Rev Microbiol. 2008;6:199-210.

3. Krzyściak W, Jurczak A, Kościelniak D, Bystrowska B, Skalniak A. The virulence of Streptococcus mutans and the ability to form biofilms. Eur J Clin Microbiol Infect Dis. 2014;33:499-515.

4. Marsh PD. Dental plaque as a microbial biofilm. Caries Res. 2004;38:204-11.

5. Socransky SS, Haffajee AD. Dental biofilms: difficult therapeutic targets. Periodontol. 2000;2002(28):12-55.

6. Roberts FA, Darveau RP. Microbial protection and virulence in periodontal tissue as a function of polymicrobial communities: symbiosis and dysbiosis. Periodontol. 2000;2015(69):18-27.

7. Marsh PD, Head DA, Devine DA. Ecological approaches to oral biofilms: control without killing. Caries Res. 2015;49(Suppl 1):46-54.

8. Escribano M, Figuero E, Martin C, Tobías A, Serrano J, Roldán S, Herrera D. Efficacy of adjunctive anti-plaque chemical agents: a systematic review and network meta-analyses of the Turesky modification of the Quigley and Hein plaque index. J Clin Periodontol. 2016;43:1059-73.

9. Marsh PD. Controlling the oral biofilm with antimicrobials. J Dent. 2010; 38(Suppl 1):S11-5.

10. Corbin A, Pitts B, Parker A, Stewart PS. Antimicrobial penetration and efficacy in an in vitro oral biofilm model. Antimicrob Agents Chemother. 2011;55:3338-44.

11. Takenaka S, Trivedi HM, Corbin A, Pitts B, Stewart PS. Direct visualization of spatial and temporal patterns of antimicrobial action within model oral biofilms. Appl Environ Microbiol. 2008:74:1869-75.

12. Yamaguchi M, Noiri Y, Kuboniwa M, Yamamoto R, Asahi Y, Maezono H, Hayashi M, Ebisu S. Porphyromonas gingivalis biofilms persist after chlorhexidine treatment. Eur J Oral Sci. 2013;121:162-8.

13. Ohsumi T, Takenaka S, Wakamatsu R, Sakaue Y, Narisawa N, Senpuku H, Ohshima H, Terao Y, Okiji T. Residual structure of Streptococcus mutans biofilm following complete disinfection favors secondary bacterial adhesion and biofilm redevelopment. PLoS One. 2015;10:e0116647.

14. Cieplik F, Jakubovics NS, Buchalla W, Maisch T, Hellwig E, Al-Ahmad A. Resistance toward chlorhexidine in oral bacteria - is there cause for concern? Front Microbiol. 2019;10:587.

15. Saleem HG, Seers CA, Sabri AN, Reynolds EC. Dental plaque bacteria with reduced susceptibility to chlorhexidine are multidrug resistant. BMC Microbiol. 2016;16:214.

16. Oda M, Yamamoto H, Shibutani M, Nakano M, Yabiku K, Tarui T, Kameyama N, Shirakawa D, Obayashi S, Watanabe N, Nakase H, Suenaga M, Matsunaga Y, Nagahama M, Takahashi H, Imagawa H, Kurosawa M, Terao Y, Nishizawa M, Sakurai J. Vizantin inhibits endotoxin-mediated immune responses via the TLR4/MD-2 complex. J Immunol. 2014;193:4507-14.

17. Takenaka S, Oda M, Domon H, Ohsumi T, Suzuki Y, Ohshima H, Yamamoto $\mathrm{H}$, Terao $\mathrm{Y}$, Noiri Y. Vizantin inhibits bacterial adhesion without affecting bacterial growth and causes Streptococcus mutans biofilm to detach by altering its internal architecture. Biochem Biophys Res Commun. 2016;480: $173-9$. 
18. Senadheera D, Cvitkovitch DG. Quorum sensing and biofilm formation by Streptococcus mutans. Adv Exp Med Biol. 2008;631:178-88.

19. Yoshida A, Ansai T, Takehara T, Kuramitsu HK. LuxS-based signaling affects Streptococcus mutans biofilm formation. Appl Environ Microbiol. 2005;71: 2372-80.

20. Burnie JP. Brooks W, Donohoe M, Hodgetts S, al-Ghamdi a, Matthews RC. Defining antibody targets in Streptococcus oralis infection. Infect Immun. 1996;4:1600-8.

21. Nibali $L$, Henderson B. The human microbiota and chronic disease: Dysbiosis as a cause of human pathology. Oxford: John Wiley \& Sons, Inc.; 2016.

22. Zhou P, Li X, Qi F. Identification and characterization of a haem biosynthesis locus in Veillonella. Microbiology. 2016;162:1735-43.

23. Izano EA, Wang H, Ragunath C, Ramasubbu N, Kaplan JB. Detachment and killing of Aggregatibacter actinomycetemcomitans biofilms by dispersion B and SDS. J Dent Res. 2007;86:618-22.

24. Wiater A, Szczodrak J, Pleszczyńska M. Mutanase induction in Trichoderma harzianum by cell wall of Laetiporus sulphureus and its application for mutan removal from oral biofilms. J Microbiol Biotechnol. 2008;18:1335-41.

25. Nguyen PTM, Falsetta ML, Hwang G, Gonzalez-Begne M, Koo H. aMangostin disrupts the development of Streptococcus mutans biofilms and facilitates its mechanical removal. PLoS One. 2014;9:e111312.

26. Lim JH, Song SH, Park HS, Lee JR, Lee SM. Spontaneous detachment of Streptococcus mutans biofilm by synergistic effect between zwitterion and sugar alcohol. Sci Rep. 2017;7:8107.

27. Yoshida Y, Konno H, Nagano K, Abiko Y, Nakamura Y, Tanaka Y, Yoshimura F. The influence of a glucosyltransferase, encoded by gtfP, on biofilm formation by Streptococcus sanguinis in a dual-species model. APMIS. 2014 122:951-60.

28. Vickerman MM, Minick PE, Mather NM. Characterization of the Streptococcus gordonii chromosomal region immediately downstream of the glucosyltransferase gene. Microbiology. 2001;147(Pt 11):3061-70.

29. Ricker A, Vickerman M, Dongari-Bagtzoglou A. Streptococcus gordoni glucosyltransfearase promotes biofilm interactions with Candida albicans. Oral Microbiol. 2014;6. https://doi.org/10.3402/jom.v6.23419.

30. Bowen WH, Koo H. Biology of Streptococcus mutans-derived glucosyltransferases: role in extracellular matrix formation of cariogenic biofilms. Caries Res. 2011;45:69-86.

31. Ooshima T, Matsumura M, Hoshino T, Kawabat S, Sobu S, Fujiwara T. Contributions of three glycosyltransferases to sucrose-dependent adherence of Streptococcus mutans. J Dent Res. 2001;80:1672-7.

32. Matsumoto M, Fujita K, Ooshima T. Binding of glucan-binding protein C to GTFD-synthesized soluble glucan in sucrose-dependent adhesion of Streptococcus mutans. Oral Microbiol Immunol. 2006;21:42-6.

33. McNab R, Ford SK, El-Sabaeny A, Barbieri B, Cook GS, Lamont RJ. LuxS-based signaling in Streptococcus gordonii: autoinducer 2 controls carbohydrate metabolism and biofilm formation with Porphyromonas gingivalis. J Bacteriol. 2003:185:274-84.

34. Cuadra-Saenz G, Rao DL, Underwood AJ, Belapure SA, Campagna SR, Sun Z, Tammariello S, Rickard AH. Autoinducer-2 influences interactions amongst pioneer colonizing streptococci in oral biofilms. Microbiology. 2012;158(Pt 7):1783-95.

35. He Z, Liang J, Tang Z, Ma R, Peng H, Huang Z. Role of the luxS gene in initial biofilm formation by Streptococcus mutans. J Mol Microbiol Biotechnol. 2015;25:60-8.

36. Chaudhuri B, Rojek J, Vickerman MM, Tanzer JM, Scannapieco FA. Interaction of salivary alpha-amylase and amylase-binding-protein a (AbpA) of Streptococcus gordonii with glucosyltranseferase of S. gordonii and Streptococcus mutans. BMC Microbiol. 2007;7:60.

37. Rogers JD, Palmer RJ Jr, Kolenbrander PE, Scannapieco FA. Role of Streptococcus gordonii amylase-binding protein a in adhesion to hydroxyapatite, starch metabolism, and biofilm formation. Infect Immun 2001:69:7046-56

38. Matsumoto-Nakano M, Tsuji M, Amano A, Ooshima T. Molecular interactions of alanine-rich and proline-rich regions of cell surface protein antigen $\mathrm{C}$ in Streptococcus mutans. Oral Microbiol Immunol. 2008;23:265-70.

39. Oda M, Kurosawa M, Yamamoto $H$, Domon $H$, Kimura $T$, Isono $T$, Maekawa T, Hayashi N, Yamada N, Furue Y, Kai D, Terao Y. Sulfated vizantin induces the formation of macrophage extracellular traps. Microbiol Immunol. 2018 62:310-6.
40. Kurosawa M, Oda M, Domon H, Saitoh I, Hayasaki H, Terao Y. Streptococcus pyogenes CAMP factor attenuates phagocytic activity of RAW 264.7 cells. Microbes Infect. 2016;18:118-27.

41. Huang X, Zhang K, Deng M, Exterkate RAM, Liu C, Zhou X, Cheng L, Ten Cate JM. Effect of arginine on the growth and biofilm formation of oral bacteria. Arch Oral Biol. 2017:82:256-62.

42. Buskermolen JK, Janus MM, Roffel S, Krom BP, Gibbs S. Saliva-derived commensal and pathogenic biofilms in a human gingiva model. J Dent Res. 2018:97:201-8.

43. Janus MM, Keijser BJ, Bikker FJ, Exterkate RA, Crielaard W, Krom BP. In vitro phenotypic differentiation towards commensal and pathogenic oral biofilms. Biofouling. 2015;31:503-10

44. Sedlacek MJ, Walker C. Antibiotic resistance in an in vitro subgingival biofilm model. Oral Microbiol Immunol. 2007;22:333-9.

45. Maki T, Ishikawa A, Mastunaga T, Pointing SB, Saito Y, Kasai T, Watanabe K, Aoki K, Horiuchi A, Lee KC, Hasegawa H, Iwasaka Y. Atmospheric aerosol deposition influences marine microbial communities in oligotrophic surface waters of the western Pacific Ocean. Deep Sea Res I. 2016;118:37-45.

46. Childers NK, Osgood RC, Hsu KL, Manmontri C, Momeni SS, Mahtani HK, Cutter GR, Ruby JD. Real-time quantitative polymerase chain reaction for enumeration of Streptococcus mutans from oral samples. Eur J Oral Sci. 2011:119:447-54.

47. Huang R, Zhang J, Yang XF, Gregory RL. PCR-based multiple species cell counting for in vitro mixed culture. PLoS One. 2015;10:e0126628.

48. Matsuda K, Tsuji H, Asahara T, Kado Y, Nomoto K. Sensitive quantitative detection of commensal bacteria by rRNA-targeted reverse transcriptionPCR. Appl Environ Microbiol. 2007;73:32-9.

49. Zhou Y, Yang J, Zhang L, Zhou X, Cisar JO, Palmer RJ Jr. Differential utilization of basic proline-rich glycoproteins during growth of oral bacteria in saliva. Appl Environ Microbiol. 2016;82:5249-58.

50. Gilmore KS, Srinivas P, Akins DR, Hatter KL, Gilmore MS. Growth development, and gene expression in a persistent Streptococcus gordonii biofilm. Infect Immun. 2003:71:4759-66.

51. Moraes JJ, Stipp RN, Harth-Chu EN, Camargo TM, Höfling JF, Mattos-Graner RO. Two-component system VicRK regulates functions associated with establishment of Streptococcus sanguinis in biofilms. Infect Immun. 2014;82:4941-51.

52. Okinaga T, Niu G, Xie Z, Qi F, Merritt J. The hdrRM operon of Streptococcus mutans encodes a novel regulatory system for coordinated competence development and bacteriocin production. J Bacteriol. 2010;192:1844-52.

53. Sun M, Kang Q, Li T, Huang L, Jiang Y, Xia W. Effect of high-fructose corn syrup on Steptococcus mutans virulence gene expression and on tooth demineralization. Eur J Oral Sci. 2014;122:216-22.

54. Zhou Y, Millhouse E, Shaw T, Lappin DF, Rajendran R, Bagg J, Lin H, Ramage G. Evaluating Streptococcus mutans strain dependent characteristics in a polymicrobial biofilm community. Front Microbiol. 2018;9:1498.

55. Zhu B, Song L, Kong X, Macieod LC, Xu P. A novel regulator modulates glucan production, cell aggregation and biofilm formation in Streptococcus sanquinis SK36. Front Microbiol. 2018:9:1154.

56. Desa MN, Navaratnam P, Vadivelu J, Sekaran SD. Expression analysis of adherence-associated genes in pneumococcal clinical isolates during adherence to human respiratory epithelial cells (in vitro) by real-time PCR. FEMS Microbiol Lett. 2008;288:125-30.

57. Liu C, Worthington RJ, Melander C, Wu H. A new small molecule specifically inhibits the cariogenic bacterium Streptococcus mutans in multispecies biofilms. Antimicrob Agents Chemother. 2011;55:2679-87.

58. Park $\mathrm{H}$, Kim KH, Andrade AL, Briles DE, McDaniel LS, Nahm MH. Nontypeable pneumococci can be divide into multiple cps types, including one type expressing the novel gene pspK. mBio. 2012;3:e00035-12.

59. Yamaguchi $M$, Minamide $Y$, Terao $Y$, Isoda R, Ogawa $T$, Yokota $S$, Hamada S, Kawabata S. Nrc of Streptococcus pneumoniae suppresses capsule expression and enhances anti-phagocytosis. Biochem Biophys Res Commun. 2009;390:155-60.

60. Zhang Y, Lei Y, Nobbs A, Khammanivong A, Herzberg MC. Inactivation of Streptococcus gordonii SspAB alters expression of multiple adhesin genes. Infect Immun. 2005;73:3351-7.

61. Schlafer S, Meyer RL, Sutherland DS, Städler B. Effect of osteopontin on the initial adhesion of dental bacteria. J Nat Prod. 2012:75:2108-12.

\section{Publisher's Note}

Springer Nature remains neutral with regard to jurisdictional claims in published maps and institutional affiliations. 